R E S E N A S 



\section{ÁLVARO GALMÉS DE FUENTES: \\ Dialectología mozárabe, Madrid, Gredos, 1983, 380 págs. \\ Prólogo de Rafael Lapesa}

Felipe Gómez Solis

Los dialectos mozárabes estaban necesitados de un estudio que analizase, con rigor y precisión, las características fonético-fonológicas y morfológicas de las diferentes zonas de la mozarabía (Toledo, Mallorca, Valencia, Murcia, Sevilla y Granada). El libro del Álvaro Galmés de Fuentes Dialectología mozárabe constitı e una obra indispensable para cualquier investigador que se acerque, con mayor o menor profundidad, hacia el conocimiento del mozárabe, un dialecto no petrificado en su inmovilidad, "sino evolutivo y contradictorio con muchos problemas no dilucidados" (Rafael Lapesa, del prólogo, p. 7).

Es preciso subrayar, a partir de los trabajos de F. J. Simonet (Glosario de voces ibéricas y latinas usadas entre los mozárabes, Madrid, 1888, pp. 11-26) y de R. M. Pidal (Origenes del español, Madrid, Espasa Calpe, 1976 , octava edición, pp. 415 y ss.) la vigencia de la lengua de los mozárabes, que pervivió en una época extremadamente difícil, sobre todo ante el advenimiento de dos fanáticas dinastías africanas, los almorávides y los almohades, en 1099 y 1146 respectivamente, conservando la cultura autóctona, como se observa en el más extraordinario poeta de la España musulmana, Ben Quzmán (1080-1160), autor de innumerables zéjeles ( Vid. el ingente estudio de Emilio García Gómez Todo Ben Quzmán, Madrid, Gredos, 1972, 3 vols., y Rafael Lapesa, Historia de la lengua española, Madrid, Gredos, 1981, p. 132). Además, es ya un lugar común el influjo de los mozarabismos en el castellano (por ejemplo, los sufijos -acho y -uto-uta o la aglutinación del 
artículo a la palabra) y en el andaluz actual (Vid. los arcaísmos léxicos, Rafael Lapesa, Historia de la lengua española, ob. cit., p. 513).

A.G., en primer lugar, expone las fuentes a las que ha acudido (1.0, los glosarios latino-árabes o hispano-árabes, como el Vocabulista arábigo en letra castellana de fray Pedro de Alcalá, el texto más tardío de los consultados, Granada, 1505; 2. , los testimonios de los botánicos, médicos y farmacólogos hispano-árabes de finales del siglo XI o principio del XII, como'El botánico anónimo sevillano de hacia el año 1.100 o el Vocabulista arábigo-latino de R. Martí, de mediados del XIII, y los cancioneros de la España musulmana, como el de Ben Quzmán; 3.०, los Libros de Repartimientos de Mallorca, Valencia, Murcia y Sevilla, en donde aparecen inventariados los nombres de los lugares, predios y propietarios árabes, y $4 .^{\circ}$, con menor intensidad, una literatura en latín tardio o medieval) y aplica a cada una de ellas, con un buen criterio, un tratamiento metodológico específico, con lo que no mezcla las fuentes, evitando incluir en un mismo saco todos los testimonios del mozárabe. Asi, en los Libros de Repartimientos A. G. elimina las capas envolventes, como los posibies influjos arábigo, latino, castellano o catalán, y analiza, por consiguiente, los fenómenos lingüísticos que son exclusivamente autóctonos.

En segundo término, A. G., que se sirve de sus propios trabajos publicados o en prensa desde 1950, afronta el espinoso problema de las transliteraciones, pues la mayor parte de los mozarabismos se han transmitido en caracteres arábigos y, por tanto, este hecho incuestionable añade una sensarión de inseguridad nara el estudiosn Sin embargo. arre. mete con decisión tal tarea acudiendo, con todo rigor, a la fuente originaria y valiéndose, sobre todo, de unos importantes documentos aljamiados de los moriscos de Valencia, descubiertos por Ana Labarta. Además, distingue el sistema de transliteración de los moriscos hispanófonos, más foneticista, y el de los arabófonos, más arbitrario, y rechaza cualquier transliteración acrítica, como la tradicional y la de M. Sanchis Guarner o E. Veres d'Ocón (claro está, A. G. se une a las investigaciones de R. M. Pidal y D. A. Griffín).

Las dificultades de las transliteraciones estriban en las propias características lingüísticas del árabe, transmisor de los mozarabismos. Así, el sistema fonológico arábigo de las vocales se reduce a tres $(a, i, u) \mathrm{y}$, como es lógico, la reproducción de e y o entraña conjeturas e hipótesis. Igualmente, tal reducido sistema vocálico -que, por el contrario, es muy rico en variantes fonéticas- no presenta diptongos crecientes y dificulta la existencia de la diptongación en el mozárabe. Pero este problema -creemos- está ya solucionado con la tesis diptongacionista, apoyada por Pidal y el propio autor de este manual, que se confirma, además, con los últimos documentos analizados por Ana Labarta (tam- 
bién, Manuel Alvar en Textos hispánicos dialectales. Antologia históri$c a$, I, Madrid, C. S. I. C., 1960, p. 3, es partidario de la diptongación y Friedrich Schürr piensa que la generalización de los diptongos estaba en curso y que no había acabado por falta de una cohesión lingüística bajo la dominación del árabe como lengua oficial e instrumento de una civilización superior, La diptongaison Romane, Tubingen, 1970, pp. 104-105). Las soluciones contradictorias entre la diptongación y la no diptongación se aprecian en el trabajo de A. G., pero "el que aparezcan en el Repartimiento [de Sevilla] algunos excepcionales ejemplos en los que una $\succ$ y una $\zeta$ tónicas del latín no diptongan. no es objeción en contra de una ley mozárabe de diptongación" (p. 189). Por otra parte, el sistema de transliteración de las consonantes es menos complejo, pues tan sólo el árabe carece del fonema bilabial oclusivo sordo $/ \mathrm{p} /$ y de la labiodental sonora [v].

La Dialectología mozárabe se divide en dos partes: 1), "Análisis de los principales dialectos mozárabes" y 2), "Análisis de algunos problemas de la dialectología mozárabe". Además, contiene un apéndice final -muy útil- sobre los mozarabismos del castellano y los romancismos del poeta cordobés Ben Quzmán. En la primera parte se estudia por separado cada una de las zonas de la mozarabía, como los dialectos mozárabes toledano, levantino de Mallorca y Valencia (se incluye aisladamente el de Murcia), sevillano y granadino, ciñéndose a las peculiaridades fonético-fonológicas, y no faltan las características morfológicas (Cfr. las páginas 109-114, 183-184, 207-212, 302-320 y 326-328). En la segunda, A. G. analiza tres problemas que atañen a la dialectología mozárabe: evolución de $l$ - inicial, resultados de $-l l-,-l y-$ y $-c^{\prime} l-$ y plurales femeninos. A continuación, resumimos los fenómenos fonético-fonológicos y morfológicos que unen a todos los dialectos mozárabes.

\section{Fenómenos fonético-fonológicos:}

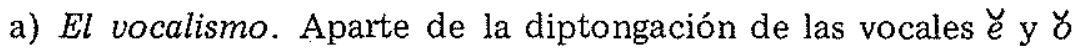
tónicas del latín, junto a casos sin diptongar (por presión latinista o catalanizante), los dialectos mozárabes vacilan entre la conservación y la pérdida de la vocal final, especialmente -o (la pérdida de -o se debe a influjo superestrático del árabe, que tiende a suprimir las vocales finales, y no tanto a una evolución interna románica o a influjo catalán, como sería obvio en el levantino). Además, el toledano distingue entre $u$ breve y $o$ larga finales, como en algunos dialectos de la Romania (asturiano y sardo logurodés).

Los diptongos decrecientes $\mathrm{AU}$ y $\mathrm{AI}$ presentan un comporta- 
miento distinto (la norma general es la conservación). Mientras que $\mathrm{AU}$ cambia sólo a ai o ey -ni siquiera toma la forma intermedia ou, y raras veces $o$, excepto en el Repartimiento de Sevilla-, AI se muestra más evolucionado, pues monoptonga en $e$, pasando por el estadio intermedio ei (R. M. Pidal admitió los tres grados: ai, ei y e).

b) El consonantismo. A. G. revisa críticamente algunas cuestiones oscuras rechazando y corraborando hipótesis, como la evolución de la $l$-inicial, la sonorización de las consonantes sordas intervocálicas y la evolución de los grupos $-l l-,-l y-$ y $-c^{\prime} l$.

El problema de la evolución de $l$ - inicial -al que el autor dedica un capítulo globalizador, pp. 247-254- se halla lejos de estar resuelto. La palatalización -que no se da en el árabe, apoyada por R. M. Pidal, H. Meier, A. Zamora Vicente, R. Lapesa y A. Kuhn y puesta en entredicho por V. García de Diego, D. A. Griffin, G. Rohlfs, entre otrosconfirma la autoctonía de tal fenómeno en el mozárabe y, además, los muchos ejemplos significativos prueban "la existencia en los dialectos mozárabes de la tendencia a palatalizar la $l$ - inicial" (p. 254).

La sonorización de las consonantes sordas intervocálicas es otra de las cuestiones más debatidas en la dialectología mozárabe. A. G. es partidario de la sonorización en Toledo, Murcia, Sevilla y Granada, aunque no aparezca la consonante sonora, como ocurre en Sevilla o Granada -esta excepción fue ya explicada por R. M. Pidal-, frente a autores que la rechazan, como Meyer Lübke y M. Sanchis Guarner.

El resultado de $-l l-,-l y-$ y $-c^{\prime} l$ - en los dialectos constituye una compleja e intrincada cuestión fonética (pp. 255-301). A. G. se basa en dos fuentes distintas (El anónimo sevillano de hacia el año $1.100, \mathrm{pu}-$ blicado por Asín Palacios, y el Vocabulista de R. Martí de la segunda mitad del XIII, analizado por D. A. Griffin) y llega a la conclusión de que existe una clara oposición entre - $l l$-, representada por la grafía $l l, \mathrm{y}$, por otra parte, $-l y-,-c^{-} l-$, representadas por las grafías $l y$. Tal oposición proporcionaría el siguiente resultado:

\begin{tabular}{|c|c|c|c|c|}
\hline & Grafía & Sonido & & Ejemplo \\
\hline 1) $-l l-$ & 11 & {$[1]$} & $\cdots$ & [ kabálu] ] \\
\hline 2) $-l y-y$ & ly & {$\left[d^{y}\right] \circ\left[y^{\prime}\right]$} & & [fídü] \\
\hline$-c^{\prime} l-$ & & & & [fiytu] \\
\hline
\end{tabular}

Por tanto, el resultado de $-l l$ - latinas no debía mantenerse en los dialectos mozárabes en la realización geminada originaria, sino que ha- 
bría llegado a un resultado palatal, y $-l l-$ y $-l y-,-c^{\prime} l-$ representan dos sonidos palatales diferenciados fonética y fonológicamente.

Otros fenómenos que se destacan son:

La $f$ - inicial se mantiene y, en otros casos, es sustituida por una aspirada -en Toledo es laríngea. A. G. piensa que tal evolución es una característica esporádica del mozárabe y no descarta la tesis sustratística de influjo ibérico de R. M. Pidal.

$G e, i$ y $j$-iniciales latinas se conservan generalmente en la mayoría de los dialectos mozárabes en forma de [y]. Sin embargo, se conocen casos de pérdida, tal como sucede en el castellano. Esta solución contradictoria apoya la tesis de Yakov Malkiel, según la cual debieron coexistir en el centro y oeste de la Península dos tendencias respecto a la $g$ y $j$ iniciales, una conservadora (oeste) y otra progresista (Castilla). En todo caso, en el mozárabe habría dominado la moda conservadora y habrían existido restos de pérdida muy abundantes en Sevilla.

$C e, i, c y$ y ty ofrecen soluciones muy distintas. En primer término, la $c$ velar latina ante una vocal anterior y ante yod evoluciona hacia una palatal -generalmente $/ \hat{c} /$ grafía $c h$ - como en italiano y rumano. En segundo lugar, la consonante evoluciona hacia una sibilante dental, representada por las grafías $\mathrm{c}$, ç y $\mathrm{z}$, que culminaría en el sonido [ts]. La solución palatal, según Amado Alonso, se produciría al tiempo de la conquista musulmana, mientras que la realización dental constituiría una evolución posterior.

Los grupos iniciales latinos $\mathrm{cl}$, $\mathrm{pl}$ - y $\mathrm{fl}$ - se mantienen en todas las zonas (sólo en el Vocabulista de fray Pedro de Alcalá se ha hallado un caso de palatalización de $p l$-).

Los grupos $-m b-\mathrm{y}-n d$ - permanecen e, igualmente, $-t r-\mathrm{y}-d r$. Pero $-k t$ - y -ult-ofrecen un estadio más evolucionado, al aparecer un resultado / $/$ /, grafía $c h$, en Toledo y un caso en Sevilla (además, en otras zonas, como Murcia, sólo se palataliza la $k$, [it]).

Los grupos con yod $-b y-\mathrm{y}-d y$-presentan en todo el territorio mozárabe dos soluciones bien contradictorias: conservación y palatalización. Sin embango, $-n y-\mathrm{y}-n n$ - tienden a una palatalización general en [y].

Otros grupos, como -mn-, -nf-, -rs- y $-n s-$ asimilan sus elementos, e incluso los romances -como $-m$ ' $n$ - - conservan sus componentes.

Finalmente, el yeísmo temprano entre los mozárabes, especialmente en Toledo y un caso aislado en el Vocabulista de fray Pedro de Alcalá, es otro problema de una dialectología mozárabe. Rafael Lapesa ha demostrado la confusión $/ \frac{1}{y} / \mathrm{y} / \mathrm{y} /$ en textos medievales, como en Juan Ruiz o en el Libro de Alexandre. 


\section{Fenómenos morfológicos}

Los fenómenos morfológicos en los dialectos mozárabes son menos frecuentes que los fonético-fonológicos, ya que apenas existen textos. A. G. analiza en un capítulo de carácter global la cuestión de los plurales femeninos en es (pp. 307-318) con una gran cantidad de ejemplos, sobre todo topónimos, y concluye en una evolución $-a s>-e s$, general a la mozarabía. Tal evolución -que aparece también en el asturleonés central- no se debe a influjo catalán en las zonas colindantes con el castellano o portugués, que mantienen sin modificar los plurales femeninos, y constituye, por tanto, una característica peculiar y genuina del mozárabe.

Aparte de estudiarse algunos plurales árabes, se analizan el género de los sustantivos y adjetivos, los sufijos más representativos - en-ena, -in-ina o acho- - y la supresión de la preposición de de los genitivos.

Junto a los fenómenos fonético-fonológicos y morfológicos, A. G., con un buen criterio, desarrolla en cada dialecto un analisis comparativo con las lenguas y dialectos de la Península Ibérica, incluido el portugués. A continuación, resumimos las afinidades y diferencias:

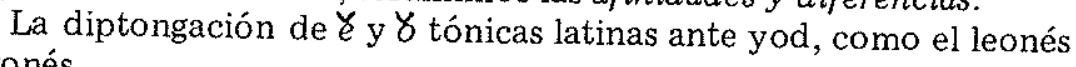
$y$ aragonés.

Se dan algunos casos de pérdida de la vocal final, en contra de lo que ocurre en castellano, leonés y aragonés, pero coincide con el catalán y, sobre todo, con el árabe.

Se conservan los diptongos decrecientes $\mathrm{AU}$ y $\mathrm{AI}$, como en gallego-portugués y en el extremo occidental de los dialectos leoneses.

Se mantiene diferenciado en el dialecto mozárabe de Toledo el timbre de las vocales $u$ breve y o larga finales, como en el leonés.

Se mantienen sin modificar los grupos iniciales latinos $\mathrm{cl}$,, $\mathrm{pl}$ - y $\mathrm{fl}-$, como en catalán, frente a las palatalizaciones del castellano, leonés y gallego-portugués.

La $l$-inicial se palataliza, como en leonés y catalán.

El grupo latino - $m b$ - se conserva, como en leonés y gallego-portugués, frente al catalán, aragonés y castellano.

Se produce la sonorización de las consonantes sordas intervocálicas, fenómeno común a la Romania Occidental.

Tendencia a modificar el timbre vocálico de los plurales femeninos en $-a s>-e s$, como sucede en el leonés central y catalán.

Esta Dialectología mozárabe representa, pues, un gran avance en el conocimiento de los dialectos mozárabes. A. Galmés ha impuesto el máximo rigor, al estudiar cada zona aisladamente y con innumerables 
ejemplos, obteniendo, de esta forma, las peculiaridades lingüísticas de Toledo, Mallorca y Valencia, Murcia, Sevilla y Granada, despojadas de los influjos de otras lenguas y dialectos. Ya se dispone de un manual en donde se recogen las características fonético - fonológicas v morfológicas de todo el territorio mozárabe. Ademas, se agradece la claridad de exposición. incluso en cuestiones tan extremadamente difíciles, como el problema de las transliteraciones o la evolución de $-l l-. l y-y c^{\prime} l$. en unos momentos de confusión terminológica. Por todo ello, A. Galmés consigue -aunque él no lo pretendiera- un estudio completo y sistemático sobre los problemas que plantea la lengua de los mozárabes. 